\title{
A Theory of Quantitative Easing Policy and Negative Interest Policy Based on the Japanese Experience
}

\author{
Masayuki Otaki*
}

Institute of Social Sciences, The University of Tokyo, Japan

\begin{abstract}
Using a two-period overlapping-generations model, I elucidate how quantitative easing policy and negative interest policy affect an economy based on the Japanese experience under the Abe cabinet. Quantitative easing policy forces a huge amount of money hoarding. Accordingly, the rate of return for money is required to rise. This implies that disinflation and/or deflation are accelerated in Japan, which is in line with reality. On the other hand, quantitative easing policy stimulates the aggregate demand, which brings about a mild recovery in business. The business upturn tightens the foreign market because of an increase in imports and causes the home currency to depreciate.

Negative interest policy implies there is a tax levied on money hoarding. Hence, as longas the government expenditure is kept constant, money circulating in an economy decreases, thereby discouraging business. Such a downturn reduces aggregate income and imports. This induces excess supply of foreign exchange. Consequently, the exchange rate appreciates to equilibrate the market.

These characteristics of the business cycle in conjunction with changes in the attitude of the monetary authority are entirely consistent with the current Japanese experience under Abenomics.
\end{abstract}

Keywords: Quantitative easing monetary policy, negative interest policy, Abenomics.

\section{INTRODUCTION}

It seems that a great many economists are not aware that there are two methods for controlling widely defined liquidity (roughly speaking, money stock plus short-term public debt) by a monetary authority in an era of historically low interest. One is open market operations targeting long-term public debt. A huge amount of the liquidity is provided via this method in developed economies, and it is dubbed quantitative easing (QE) monetary policy.

Even though QE policy is significant, the other method for defining widely defined liquidity is not trivial. Japan experiences arbitrage between interest accruing from excess reserves and interest from short-term public debt. When the former is set negative, the short term interest rate follows suit. Negative reserve interest is the tax levy on hoarding high-powered money. To put it more generally, lowering the rate of interest for excess reserves certainly reduces the quantity of widely defined liquidity because such a policy lowers the rate of return for near money assets via arbitrage. This is the other procedure for controlling the widely defined liquidity.

Accordingly, the policy mix of QE policy and negative reserve interest is mutually contradictory as follows. QE policy brings about a mild recovery by the multiplier effect, which is theorized by Otaki (2015) in

*Address correspondence to this author at the 7-3-1 Hongo Bunkyo, Tokyo, 113-0033, Japan; Tel: +81-3-5874-4952; Fax: +81-3-5841-4905;

E-mail: ohtaki@iss.u-tokyo.ac.jp conjunction with a higher rate of return for widely defined liquidity, which implies the acceleration of disinflation and/or deflation. Such a recovery increases imports; and thus, the foreign exchange market falls in excess supply of the home currency. Accordingly, QE policy causes the exchange rate to depreciate. Japan experienced a mild recovery coinciding with the acceleration of disinflation and a weak Japanese yen under the Abe cabinet until negative reserve interest policy was enacted.

Negative reserve interest policy, on the other hand, shrinks the quantity of widely defined liquidity. Consequently, an economy falls into stagnation alongside an appreciation of the home currency and a fall in the real rate of return for money as experienced in the Japanese economy currently. ${ }^{1}$

The rest of this paper is organized as follows. Section 2 constructs a model of a small open economy based on Otaki $(2012,2015)$. The consequences of QE policy and negative interest policy are analyzed in Section3. Section 4 provides brief concluding remarks.

\section{THE MODEL}

\subsection{The Structure of the Model}

Let us consider a two-period overlappinggenerations model of the production economy with

${ }^{1}$ Whether disinflation and/or deflation are resolved is ambiguous because we cannot predict how seriously a change in the nominal rate of interest (the interest accruing from excess reserves) affects the real rate of interest. 
infinite time horizon. This small open economy under a flexible exchange rate system consumes two types of goods: goods, $x$, in which the economy specializes; goods, $y$, which are produced in the rest of the world and are circulated internationally. The only production resource is labor. For simplicity, let us assume that one unit of labor produces one unit of goods, $x$, and that the opportunity to of work, which means the opportunity to earn income, is limited within the young generation.

There are two assets accruing no nominal interest: the home currency and the foreign currency. Goods in each economy are purchasable only by its own currency. It is assumed that no individual has an inheritance motive, and the balance of payments must be equilibrated always. Specifically, the surplus in the balance of payments implies precisely that members of the old generation of the home economy bequeaths the foreign currency to their descendant because international loans between the same generations are unfeasible by the synchronization of the earning opportunity. In the opposite case, that is, when the balance of payments falls in deficit, the old generation becomes bankrupt; and thus, rational young individuals never sell their produced goods in advance.

\subsection{Individuals}

The utility function $U$ of the residents of this economy is identical:

$U \equiv u\left(c_{1 t}, c_{2 t+1}\right)-\delta_{t} \alpha, c_{i t} \equiv\left[x_{i t}\right]^{\beta}\left[y_{i t}\right]^{1-\beta}, 0<\beta<1$,

where $c_{i t}$ is the composition of goods that are consumed by the $i$-th stage of life during period $t . x_{i t}$ and $y_{i t}$ are the consumption of the home and foreign goods, respectively. $\alpha$ denotes the disutility of labor. $\delta_{t}$ is a definition function that takes unity value when the individual is employed and zero when unemployed. $u(\cdot)$ is a well-behaved and homothetic utility function.

An elementary calculation leads us to the following expenditure function, $\Psi$ :

$$
\Psi \equiv \psi\left(\left[p_{t}^{x}\right]^{\beta}\left[\pi_{t} p_{t}^{y}\right]^{1-\beta},\left[p_{t+1}^{x}\right]^{\beta}\left[\pi_{t+1} p_{t+1}^{y}\right]^{1-\beta}\right) \cdot g(\bar{u}),
$$

where $p_{t}^{x}$ is the price of the home goods during period $t$, and $p_{t}^{y}$ is that of the foreign goods. $\pi_{t}$ denotes the nominal exchange rate. From the linear homogeneity of the expenditure function, Equation (2) can be transformed into
$\Psi \equiv p_{t}^{x} \psi\left(\left[e_{t}\right]^{1-\beta}, \rho_{t}^{x}\left[e_{t+1}\right]^{1-\beta}\right) \cdot g(\bar{u})$

where $e_{t}$ denotes the real exchange rate during period $t$, and $\rho_{t}^{x}$ is the inflation rate in terms of the home goods. Abbreviating the adjustment process, I assume that the home economy is in a stationary state. That is,

$$
e_{t}=e, \forall t
$$

Then, Equation (3) can rewritten as

$$
\Psi \equiv p_{t}^{x}[e]^{1-\beta} \psi\left(1, \rho_{t}^{x}\right) \cdot g(\bar{u}) .
$$

\subsection{Firms}

Since every firm is assumed to be a price taker and faces the linear homogenous production function, profit becomes zero in equilibrium. Accordingly, the following equality is obtained.

$$
\begin{aligned}
& p_{t}^{x}=w_{t}^{R} \Leftrightarrow[e]^{1-\beta} \psi\left(1, \rho^{x}\right) \cdot g(\alpha)=1 ; \\
& w_{t}^{R}=p_{t}^{x}[e]^{1-\beta} \psi\left(1, \rho_{t}^{x}\right) \cdot g(\alpha),
\end{aligned}
$$

where $w_{t}^{R}$ is the nominal reservation wage, as clarified by the bottom equation in (6).

Equation (6) describes the participation constraint for individuals. This equation implies that whenever the home currency depreciates, disinflation should advance. This is because such depreciation impoverishes individuals owing to expensive import goods; and hence, the inflation rate in terms of the home good should be calmed to compensate for this disadvantage. Thus, a foreign business cycle diffuses through an adjoining change in terms of trade (the inverse of the real exchange rate). In this sense, the employment isolation effect is imperfect even though the balance of payments is always in equilibrium as Laursen and Metzler (1950) assert in the more undeveloped model.

\subsection{The Dynamics of Money Supply: Mechanism of the Negative Interest Rate}

To clarify the role of the central bank in negative interest policy, let the dynamics of money supply be formatted. The dynamics can be denoted as

$$
M_{t}=[1-\chi \cdot \theta] M_{t-1}+G,
$$

where $M_{t}$ is the home currency stock during period $t$. $\theta$ is the rate of deduction from money hoarding. $\chi$ is a 
definition function, of which the value is unity when negative interest rate policy is enforced, and zero when the policy is dismissed. $G$ is the nominal government expenditure financed by printing money. The first term of the right-hand of Equation (7) is total money after deducting imposed negative interest, which the old generation carries over. The second term is the new issue of money via fiscal expenditure.

Normalizing Equation (7) by $p_{t}^{x}$, and assuming the stationarity of the real money supply, $m$, I obtain

$$
\left[1-\frac{[1-\chi \cdot \theta]}{\rho^{x}}\right] m=g, g \equiv \frac{G_{t}}{p_{t}^{a}}=\text { const. }
$$

Equation (8) contains important information concerning the effect of the negative interest policy. For given the real expenditure, $g$, the corresponding real money supply, $m$, decreases when $\chi=1$. That is, the negative interest policy ultimately causes a monetary contraction. The reason is that, given the volume of new issue, $g$, as inflow, much money leaks from circulation and is hoarded by the central bank. In other words, the negative interest policy is a tax levy on private money hoarding. Let the relationship in Equation (8) be denoted as

$m \equiv m(\chi \cdot \theta, g), \frac{\partial m}{\partial[\chi \cdot \theta]}<0, \frac{\partial m}{\partial g}>0$.

In addition, it is assumed that the real government expenditure is distributed between the home and foreign goods by the same proportion as the propensity to expenditure of the private sector.

\subsection{Market Equilibrium}

There are four markets in this model: goods, labor, foreign currency, and home currency markets. The goods market and home currency markets are mutually dependent. Accordingly, it is necessary and sufficient for analyzing the model to focus on the goods, labor, and foreign currency markets.

The labor market equilibrium condition is described entirely by participation constraint (6). The foreign currency market is equilibrated by the following condition:

$\beta e y^{F}=[1-\beta] y^{H}$.

The left-hand side of Equation (10) represents exports of the home economy (the sum of the consumption of the younger generation, the old generation and the government in the foreign economy). $\beta$ is the expenditure propensity to the home goods, and $e y^{F}$ is the aggregate income of the foreign country in terms of home currency. The right-hand side of Equation (10) is the aggregated import demand for the foreign goods. ${ }^{2}$ This increases proportionately with the real aggregate income, $y^{H} \cdot 1-\beta$ is the expenditure propensity toward the foreign goods of the home economy. As discussed in 2.1, unless Equation (9) is upheld, old individuals bequeath some foreign money or become bankrupt. Accordingly, Equation (10) is the equilibrium condition for the foreign currency.

By using Equations (8) and (9), the equilibrium condition for the home goods market is denoted as

$s\left(\rho^{x}\right) y^{H}=m(\chi \cdot \theta, g), s\left(\rho^{x}\right) \equiv 1-c\left(\rho^{x}\right), s^{\prime}\left(\rho^{x}\right)<0$.

Equation (11) implies that the aggregate savings must be equal to the widely defined money supply, which corresponds to the sum of the expenditure of the old generation and the government. It is noteworthy that, by Equation (10), the net saving of foreign currency is always zero.

Equations (6), (10), and (11) are the structural equations in this model: Equation (6) describes the supply-side condition; Equation (10) represents the non-Ponzi condition in the foreign currency market; and Equation (11) is also interpreted as the equilibrium condition for the home currency market. There are three endogenous variables in the model; $y^{H}, \rho^{x}, e$. Accordingly, the model is closed.

\section{QE POLICY AND NEGATIVE INTEREST RATE POLICY IN A SMALL OPEN ECONOMY MODEL}

It should be noted that, in general, a two period overlapping-generations model emphasizes the role of money stock in purchasing goods than in the traditional IS-LM analysis. There is no direct effect of an increase in money on aggregate demand in the IS-LM analysis. However, the widely defined liquidity rapidly enlarges via radical QE policy as the introductory discussion suggests, money cannot only be regarded only as a measure for hoarding value, but also as a transaction medium. This implies that the purchasing power of money directly affects aggregate demand expressed as in Equation (11). Thus, an overlapping-generations model is a convenient vehicle for analyzing QE policy. ${ }^{3}$

\footnotetext{
${ }^{2}$ See Otaki (2015, p.69) for more detail on the derivation of the export and import functions.

${ }^{3}$ See Otaki (2016) for a precise discussion about the intrinsic difference between the IS-LM analysis and the two period overlapping-generations model.
} 
From the comparative statics around the equilibrium, $\left(y^{H^{*}}, \rho^{x^{*}}, e^{*}\right), \quad \mathrm{I}$ obtained the following results: ${ }^{4}$

$\frac{d y^{H^{*}}}{d m}>0, \frac{d \rho^{x^{*}}}{d m}<0, \frac{d e^{*}}{d m}>0$,

$\frac{d y^{H^{*}}}{d \theta}<0, \frac{d \rho^{x^{*}}}{d \theta}>0, \frac{d e^{*}}{d \theta}<0$, if $\chi=1$.

The upper inequalities represent the effect of QE policy to an economy. Radical monetary expansion stimulates the economy and raises the real income, $y^{H^{*}}$. On the other hand, disinflation and/or deflation advance ( $\rho^{x^{*}}$ decreases) because the rate of return for money must arise to absorb the potential excess supply in money. Meanwhile, since the business upturn increases the demand for the foreign currency, the real exchange rate depreciates ( $e^{*}$ decreases). This is the acute fact that Japan experienced under the strengthened QE policy of the Abe cabinet from the beginning of 2013 to the beginning of 2016 .

The lower inequalities in (12) show the effects of the negative interest policy. As aforementioned, the negative interest rate policy means taxation on money hoarding. Accordingly, as long as the real government expenditure, $g$, remains intact, such a policy causes a monetary contraction and thus, the effects are entirely contrary to those of QE policy.

That is, a monetary contraction provoked by the negative interest policy thwarts business and stagnation ensues. Since such economic stagnation lowers the import demand and causes excess supply of foreign currency, the real exchange rate appreciates to equilibrate the market. While it is certain that real effective interest, defined as, $\frac{1-\theta}{\rho^{x^{*}}}$, falls because widely defined liquidity becomes scarce, it is unclear whether disinflation/deflation decelerates.

As such, this model succeeds in describing macroeconomic aspects in the current Japanese economy. As far as my theory possesses relevance to the actual economy, it is apparent that QE policy contradicts negative interest policy.

\section{CONCLUDING REMARKS}

Based on a two period overlapping-generations model of a small open and production economy, I obtain the following results.

${ }^{4}$ See the Appendix for more details on this calculation.
First, a radical QE policy not only stimulates an economy but also accelerates disinflation and/or deflation. This is because rapid monetary expansion requires a higher rate of return for widely defined liquidity. In addition, higher income in conjunction with the boom increases import demand. To equilibrate the foreign currency market, the real exchange rate depreciates.

Second, the negative interest imposed on the excess reserve ultimately shrinks the supply of widely defined liquidity. This is because the negative interest means the tax levy on hoarding money. Consequently, all effects --- economic stagnation, appreciation of the home currency, and a fall of the real effective interest rate for money --- are contrary to those of QE policy.

\section{ACKNOWLEDGEMENT}

I am thankful to Takashi Unayama for his incisive comments. Any remaining errors are entirely my own. This study is supported by MEXT/JSPS KAKENHI Grant Number 60183761.

\section{APPENDIX}

By differentiating Equations (11), (10), and (6), I obtain the following simultaneous equations.

$$
\begin{aligned}
& {\left[\begin{array}{ccc}
s & s^{\prime} y^{H^{*}} & 0 \\
1-\beta & 0 & -\beta y^{F} \\
0 & \psi^{\prime}\left[e^{*}\right]^{1-\beta} & {[1-\beta] \psi\left[e^{*}\right]^{-\beta}}
\end{array}\right]} \\
& {\left[\begin{array}{c}
d y^{H^{*}} \\
d \rho^{x^{*}} \\
d e^{*}
\end{array}\right]=\left[\begin{array}{c}
d m \\
\beta e^{*} \cdot d y^{F} \\
0
\end{array}\right],}
\end{aligned}
$$

where $\psi \equiv \psi\left(1, \rho^{x^{*}}\right),\left.\psi^{\prime} \equiv \frac{\partial \psi}{\partial \rho}\right|_{\rho=\rho^{*^{*}}}$.

Solving this simultaneous equation system, the following reduced form is obtained.

$$
\begin{aligned}
& {\left[\begin{array}{c}
d y^{H^{*}} \\
d \rho^{x^{*}} \\
d e^{*}
\end{array}\right]=\frac{1}{\Delta}\left[\begin{array}{ccc}
\beta \psi^{\prime}\left[e^{*}\right]^{1-\beta} y^{F} & -s^{\prime}[1-\beta] \psi\left[e^{*}\right]^{-\beta} y^{H^{*}} & -\beta s^{\prime} y^{H^{*}} y^{F} \\
-[1-\beta]^{2} \psi\left[e^{*}\right]^{-\beta} & s[1-\beta] \psi\left[e^{*}\right]^{-\beta} & s \beta y^{F} \\
{[1-\beta] \psi^{\prime}\left[e^{*}\right]^{1-\beta}} & -s \psi^{\prime}\left[e^{*}\right]^{1-\beta} & -s^{\prime}[1-\beta] y^{H^{*}}
\end{array}\right]} \\
& {\left[\begin{array}{c}
d m \\
\beta e^{*} \cdot d y^{F} \\
0
\end{array}\right],} \\
& \Delta \equiv s \beta \psi^{\prime}\left[e^{*}\right]^{1-\beta} y^{F}-s^{\prime}[1-\beta]^{2} \psi\left[e^{*}\right]^{1-\beta} y^{H^{*}}>0 .
\end{aligned}
$$

Equation (14) implies the inequalities in (12). 


\section{REFERENCES}

Laursen, Svend and Metzler, Lloyd, A.1950. "Flexible Exchange Rates and the Theory of Employment." Review of Economic Statistics 32:281-99. http://dx.doi.org/10.2307/1925577

Otaki, Masayuki. 2012. "A Keynesian Model of a Small Open Economy under a Flexible Exchange Rate." Theoretical Economics Letters 2:278-82. http://dx.doi.org/10.4236/tel.2012.23051
Otaki, Masayuki. 2015. Keynesian Economics and Price Theory: Reorientation of a Theory of Monetary Economy. Springer, Tokyo. http://dx.doi.org/10.1007/978-4-431-55345-8

Otaki, Masayuki. 2016. Keynes's General Theory Reconsidered in the Context of the Japanese Economy. Springer-Briefs in Economics, Development Bank of Japan Research Series, Springer, Tokyo.

http://dx.doi.org/10.1007/978-4-431-55915-3

Received on 25-05-2015

DOI: http://dx.doi.org/10.6000/1929-7092.2016.05.20

(C) 2016 Masayuki Otaki; Licensee Lifescience Global.

This is an open access article licensed under the terms of the Creative Commons Attribution Non-Commercial License (http://creativecommons.org/licenses/by-nc/3.0/) which permits unrestricted, non-commercial use, distribution and reproduction in any medium, provided the work is properly cited. 